\title{
Negative Ion-Atmospheric Pressure \\ Photoionization: Electron Capture, \\ Dissociative Electron Capture, Proton Transfer, and Anion Attachment
}

\author{
Liguo Song, Amber D. Wellman, Huifang Yao, and John E. Bartmess \\ Mass Spectrometry Center, Department of Chemistry, University of Tennessee, Knoxville, Tennessee, USA
}

To better guide the development of liquid chromatography/electron capture-atmospheric pressure photoionization-mass spectrometry (LC/EC-APPI-MS) in analysis of low polarity compounds, the ionization mechanism of 19 compounds was studied using dopant assisted negative ion-APPI. Four ionization mechanisms, i.e., EC, dissociative EC, proton transfer, and anion attachment, were identified as being responsible for the ionization of the studied compounds. The mechanisms were found to sometimes compete with each other, resulting in multiple ionization products from the same molecule. However, dissociative EC and proton transfer could also combine to generate the same $[\mathrm{M}-\mathrm{H}]^{-}$ions. Experimental evidence suggests that $\mathrm{O}_{2}^{-}$, which was directly observed in the APPI source, plays a key role in the formation of $[\mathrm{M}-\mathrm{H}]^{-}$ions by way of proton transfer. Introduction of anions more basic than $\mathrm{O}_{2}^{--}$, i.e., $\mathrm{C}_{6} \mathrm{H}_{5} \mathrm{CH}_{2}^{-}$, into the APPI source, via addition of di-tert-butyl peroxide in the solvent and/or dopant, i.e., toluene, enhanced the deprotonation ability of negative ion-APPI. Although the use of halogenated solvents could hinder efficient EC, dissociative EC, and proton transfer of negative ion-APPI due to their EC ability, the subsequently generated halide anions promoted halide attachment to compounds that otherwise could not be efficiently ionized. With the four available ionization mechanisms, it becomes obvious that negative ion-APPI is capable of ionizing a wider range of compounds than negative ion chemical ionization (NICI), negative ion-atmospheric pressure chemical ionization (negative ion-APCI) or negative ion-electrospray ionization (negative ion-ESI). (J Am Soc Mass Spectrom 2007, 18, 1789-1798) (c) 2007 American Society for Mass Spectrometry

$\mathrm{I}$ $\mathrm{t}$ is well known that liquid chromatography mass spectrometry (LC/MS) favors the analysis of polar compounds, as acid-base solution reactions are the most commonly observed ionization mechanism when using electrospray ionization (ESI) and atmospheric pressure chemical ionization (APCI). Traditionally, gas chromatography mass spectrometry (GC/MS) using both electron ionization (EI) and chemical ionization (CI) is employed for the analysis of volatile and thermostable nonpolar compounds. However, it can become difficult to analyze nonvolatile and/or thermo-labile nonpolar compounds via hyphenated techniques of chromatography and MS.

In the year 2000, atmospheric pressure photoionization (APPI) [1] was developed as a complement to LC/ESI-MS and LC/APCI-MS. Presently, two fundamentally different APPI sources are commercially available [1, 2]. Syagen Technology (Tustin, CA) produces PhotoMate, and Applied Biosystems/MDS SCIEX (Concord, Ontario, Canada) markets PhotoSpray. In

Address reprint requests to Dr. L. Song, Mass Spectrometry Center, Department of Chemistry, University of Tennessee, Knoxville, TN 379961600, USA. E-mail: song@ion.chem.utk.edu both designs, photons emitted by a krypton discharge lamp are used to initiate a series of gas-phase reactions, which finally lead to analyte ionization. However, they differ in that PhotoMate utilizes a design to enhance direct APPI, while PhotoSpray implements a design using a dopant, usually toluene, to enhance ion-molecule reactions. Due to a different ionization process as compared to ESI and APCI, LC/APPI-MS is anticipated to expand the polarity range of analytes amenable to LC/MS to include low polarity compounds [3, 4]. Unfortunately, there has been little progress reported thus far [5].

Low polarity compounds with positive electron affinities (EA) can be ionized via an electron capture (EC) mechanism. Traditionally, gas chromatography electron capture-negative ion chemical ionization-mass spectrometry (GC/EC-NICI-MS) has been one of the most sensitive and specific analytical methods, and has been widely used in the analysis of natural electrophores and other compounds after electrophoric derivatization [6]. Recently, LC/EC-APCI-MS methodology [7] was developed and used to analyze some low polarity compounds. In our most recent study [8], an EC mechanism was found to be highly efficient in the 
analysis of fullerenes and perfluorinated compounds when dopant-assisted negative ion-APPI was employed. In addition, a dissociative EC mechanism was also found to be highly efficient in the analysis of pentafluorobenzyl derivatives. These results suggest that LC/EC-APPI-MS may permit the analysis of nonvolatile, low polarity compounds with the sensitivity and selectivity that GC/EC-NICI-MS delivers for volatile nonpolar compounds. However, unlike in a NICI source, a series of gas-phase reactions are expected in an APPI source, especially when using a dopant. These reactions may compete with the $\mathrm{EC}$ and/or dissociative EC ionization and result in alterations of the expected sensitivity and selectivity. The aim of this work is to study, in detail, the relevant reactions so that LC/ECAPPI-MS development can be better guided toward analysis of low polarity compounds in the future.

The basic principle of APPI is the formation of a molecular radical cation caused by the absorption of a photon by a molecule, and is accompanied by the formation of a thermal electron [9]. In dopant assisted negative ion-APPI, the ionization process is initiated by thermal electrons. Currently, subsequent ionization mechanisms including EC, dissociative EC, and proton transfer are suggested to be responsible for the formation of negative ions $[8,10,11]$. In this study, nitroaromatics were preliminarily chosen as analytes because previous studies demonstrated multiple ionization products by both EC-NICI [12, 13] and EC-APCI [1419]. Toluene was exclusively used as both dopant and solvent so that chemical reactions in the APPI source could be kept at a minimum and the formation of ionization products could be better interpreted. Other aromatics with similar structures to the nitroaromatics used were also selected and studied to better understand the proton transfer mechanism of negative ionAPPI. Anion attachment was identified as a novel ionization mechanism for negative ion-APPI. It offers the ability to ionize compounds that cannot be efficiently ionized by EC, dissociative EC, and proton transfer. The effect of solvents and buffer reagents on ionization was not the focus of this study, as it is predictable according to the ionization mechanisms and has been studied extensively in previous work [8, 11].

\section{Experimental}

\section{Reagents}

Toluene was HPLC grade and purchased from Fisher Scientific (Suwanee, GA). Methylene chloride, bromoethane, iodoethane, 2,4,6-trimethylbenzoic acid (2,4,6TMBA), decanoic acid, 4-nitroaniline, 4-nitrophenol, 3-fluoroaniline, 3-trifluoromethylaniline, 3-nitroaniline, and poly(ethylene glycol)methyl ether with average M.W. 750 (PEG methyl ether 750) were purchased from Aldrich Chemical (St. Louis, MO). 1,3-Dinitrobenzene (1,3DNB), 2-amino-4,6-dinitrotoluene (2-amino-4,6-DNT), 2,4dinitrotoluene (2,4-DNT), 2,4,6-trinitrotoluene (TNT),
1,3,5-trinitrobenzene(1,3,5-TNB), RDX, and HMX were purchased from AccuStandard (New Haven, CT). 2-Methylbenzoic acid (2-MBA) was purchased from TCI (Wellesley Hills, MA). 4-Nitrotoluene was purchased from Eastman Kodak (Rochester, NY). 2-Nitrophenyl octyl ether, 4-cyanoaniline, and di-tert-butyl peroxide were purchased from Fluka (St. Louis, MO). The structures of the studied compounds are shown in Figure 1. Their thermodynamic data is given in Table 1. The thermodynamic data of oxygen and nitrogen dioxide from the atmosphere is also given in Table 1 . The existence of oxygen in an APPI source plays a key role in negative ion-APPI [11].

\section{Apparatus}

All experiments were performed using a MDS SCIEX QSTAR XL triple quadrupole time-of-flight (QTOF) mass spectrometer (Concord, Ontario, Canada) using an APPI source with a $10 \mathrm{eV}$ krypton discharge lamp. High purity nitrogen was used for nebulizer, auxiliary, curtain, and lamp gas. A micro syringe pump (Harvard Apparatus, Holliston, MA) was used to deliver the analyte solution at a flow rate of $20 \mu \mathrm{L} / \mathrm{min}$. HPLC<smiles>O=[N+]([O-])c1cccc([N+](=O)[O-])c1</smiles><smiles>Cc1c(N)cc([N+](=O)[O-])cc1[N+](=O)[O-]</smiles><smiles>Cc1ccc([N+](=O)[O-])cc1[N+](=O)[O-]</smiles><smiles>Cc1c([N+](=O)[O-])cc([N+](=O)[O-])cc1[N+](=O)[O-]</smiles><smiles>O=[N+]([O-])c1cc([N+](=O)[O-])cc([N+](=O)[O-])c1</smiles>

(i)<smiles>Cc1ccc(N2OC3CCCCC32)cc1</smiles>

(m)<smiles>Nc1cccc(F)c1</smiles>

(n)

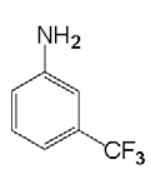

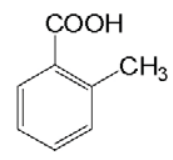

(j)<smiles>Nc1ccc([N+](=O)[O-])cc1</smiles>

(g)<smiles>Cc1cc(C)c(C(=O)O)c(C)c1</smiles>

(k)

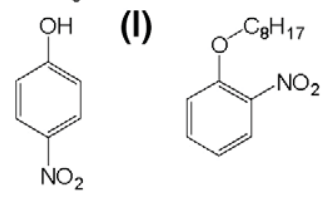

(o)

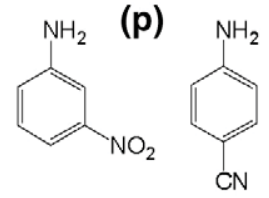

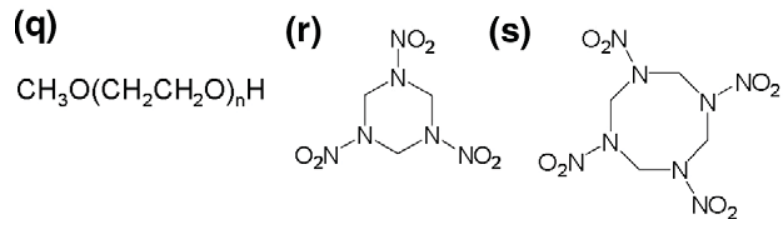

Figure 1. Structures of studied compounds: (a) 1,3-dinitrobenzene; (b) 2-amino-4,6-dinitrotoluene; (c) 2,4-dinitrotoluene; (d) 2,4,6trinitrotoluene; (e) 1,3,5-trinitrobenzene; (f) 2-methylbenzoic acid; (g) 2,4,6-trimethylbenzoic acid; (h) decanoic acid; (i) 4-nitrotoluene; (j) 4-nitroaniline; (k) 4-nitrophenol; (1) 2nitrophenyl octyl ether; (m) 3-fluoroaniline; (n) 3-trifluoromethylaniline; (o) 3-nitroaniline; (p) 4-cyanoaniline; (q) poly(ethylene glycol) methyl ether with average M.W. 750; (r) RDX; (s) HMX. 
Table 1. Thermodynamic data for studied compounds ${ }^{a}$

\begin{tabular}{|c|c|c|c|c|}
\hline Name & MW & $\mathrm{M}-\mathrm{H}$ & $\mathrm{EA}(\mathrm{eV})$ & $\Delta \mathrm{H}_{\text {acid }}(\mathrm{kcal} / \mathrm{mol})$ \\
\hline Oxygen & 31.9898 & / & $0.45^{b}$ & / \\
\hline Nitrogen dioxide & 45.9929 & l & $2.27^{\mathrm{c}}$ & / \\
\hline 1,3-Dinitrobenzene & 168.0171 & 167.0093 & $1.66^{\mathrm{b}}$ & $\sim 356^{c}$ \\
\hline 2-Amino-4,6-dinitrotoluene & 197.0437 & 196.0358 & $\sim 1.6^{c}$ & $\sim 329^{c}$ \\
\hline 2,4-Dinitrotoluene & 182.0328 & 181.0249 & $\sim 1.6^{\mathrm{c}}$ & $\sim 328^{c}$ \\
\hline 2,4,6-Trinitrotoluene & 227.0178 & 226.0100 & $\sim 2.5^{\mathrm{c}}$ & $315.6^{b}$ \\
\hline 1,3,5-Trinitrobenzene & 213.0022 & 211.9944 & $\sim 2.6^{c}$ & $\sim 340^{\mathrm{c}}$ \\
\hline 2-Methylbenzoic acid & 136.0524 & 135.0446 & $\sim 0^{\mathrm{c}}$ & $339.2^{b}$ \\
\hline 2,4,6-Trimethylbenzoic acid & 164.0837 & 163.0759 & $\sim 0^{\mathrm{c}}$ & $339.0^{\mathrm{b}}$ \\
\hline Decanoic Acid & 172.1763 & 171.1385 & $<0^{\mathrm{c}}$ & $338.8^{b}$ \\
\hline 4-Nitrotoluene & 137.0477 & 136.0399 & $0.95^{b}$ & $352.5^{b}$ \\
\hline 4-Nitroaniline & 138.0429 & 137.0351 & $0.92^{\mathrm{b}}$ & $343.5^{b}$ \\
\hline 4-Nitrophenol & 139.0269 & 138.0191 & $\sim 0.9^{c}$ & $327.8^{b}$ \\
\hline 2-Nitrophenyl octyl ether & 251.1521 & 250.1443 & $\sim 1.0^{\mathrm{c}}$ & $\sim 377^{c}$ \\
\hline 3-Fluoroaniline & 111.0484 & 110.0406 & $<0^{\mathrm{c}}$ & $361.2^{b}$ \\
\hline 3-Trifluoromethylaniline & 161.0452 & 160.0374 & $\sim 0.0^{\mathrm{c}}$ & $356.9^{b}$ \\
\hline 3-Nitroaniline & 138.0429 & 137.0351 & $0.95^{b}$ & $352.3^{b}$ \\
\hline 4-Cyanoaniline & 118.0531 & 117.0453 & $\sim 0.2^{\mathrm{c}}$ & $348.8^{b}$ \\
\hline $\mathrm{CH}_{3} \mathrm{O}\left(\mathrm{CH}_{2} \mathrm{CH}_{2} \mathrm{O}\right)_{11} \mathrm{H}$ & 516.3146 & / & $<0^{\mathrm{c}}$ & $\sim 373^{\mathrm{c}}$ \\
\hline RDX & 222.0349 & l & $<0^{\mathrm{c}}$ & $>400^{c}$ \\
\hline HMX & 296.0465 & / & $<0^{\mathrm{c}}$ & $>400^{c}$ \\
\hline
\end{tabular}

${ }^{a} E A$, electron affinity; $\Delta \mathrm{H}_{\text {acid }}$, gas-phase acidity.

bData obtained from reference [27].

'Data estimated using experimental data for structural analogs, with data from reference [27]. Uncertainties are estimated as being $\pm 5 \mathrm{kcal} / \mathrm{mol}$ for acidities, and $\pm 0.2 \mathrm{eV}$ for electron affinities.

grade toluene was used as the analyte solvent, and simultaneously served as the dopant. Therefore, the dopant delivery port of the APPI source was sealed. However, some auxiliary gas flow was necessary to achieve the best sensitivity. The general controlling parameters and settings for negative ion-APPI MS using TOFMS scan were GS1 (gas 1 or nebulizer gas), 30; GS2 (gas 2 or auxiliary gas), 30; CUR (curtain gas), 40; IS (ion spray voltage), $-1500 \mathrm{~V}$; TEM (temperature), $250{ }^{\circ} \mathrm{C}$; DP (decluster potential), $-30 \mathrm{~V}$; FP (focusing potential), $-80 \mathrm{~V}$; DP2 (decluster potential 2), $-12 \mathrm{~V}$; and CAD (collision gas), 3. The general controlling parameters for negative ion-APPI MS/MS using product ion scan were identical to the TOFMS scan with an extra parameter, collision energy (CE). The acquisition time for one spectrum was $1 \mathrm{~s}$. Although spectra of analyte mixtures are used for a concise presentation in this article, spectra of individual analytes were acquired with varying in-source fragmentation parameters, i.e., DP and TEM, so that the formation of ionization products could be correctly interpreted. In addition, the QTOF mass spectrometer offered accurate mass measurement such that we were able to investigate the elemental composition of interesting peaks in each spectrum.

\section{Results and Discussion}

\section{Background Ions}

A background spectrum of toluene using negative ion-APPI is demonstrated in Figure 2. Making use of the accurate mass measurement offered by the QTOF mass spectrometer, we were able to investigate the elemental composition of background ions. The probable structure of most background ions and the gas-phase acidity of their corresponding acids are listed in Table 2.

Previously, Kauppila et al. [11] reported the $m / z$ 46, $59,60,61$, and 77 background anions from toluene using a triple quadrupole mass spectrometer. They interpreted the $\mathrm{m} / \mathrm{z} 46,60$, and 61 anions to be $\mathrm{NO}_{2}^{-}, \mathrm{CO}_{3}^{-}$, and $\mathrm{HCO}_{3}^{-}$. Furthermore, although $\mathrm{O}_{2}^{--}$was not observed directly in a spectrum, its existence was assumed by the interpretation of ionization products of some analytes. The existence of $\mathrm{O}_{2}$ and $\mathrm{NO}_{2}$ anions was easily inferred by the ionization of atmospheric gases

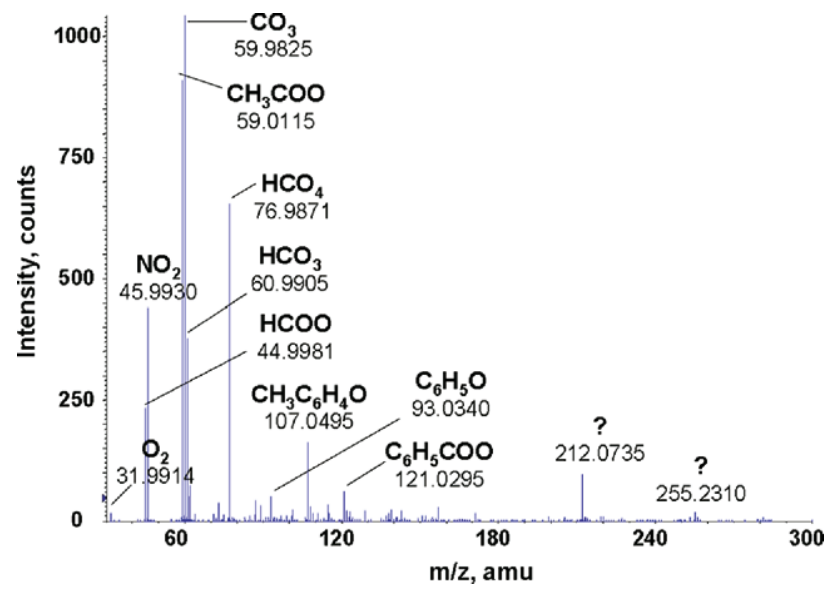

Figure 2. Background spectrum of toluene using negative ionAPPI. 
Table 2. Probable structure and thermodynamic data for background ions ${ }^{\mathrm{a}}$

\begin{tabular}{clcc}
\hline $\begin{array}{c}\text { Background } \\
\text { ions }(\mathrm{m} / \mathrm{z})\end{array}$ & \multicolumn{1}{c}{$\begin{array}{c}\text { Probable } \\
\text { structure }\end{array}$} & $\begin{array}{c}\text { Theoretical } \\
\mathrm{m} / \mathrm{z}\end{array}$ & $\Delta \mathrm{H}_{\text {acid }}(\mathrm{kcal} / \mathrm{mol})$ \\
\hline \hline 31.9914 & $\mathrm{O}_{2}^{-}$ & 31.9898 & $353.0^{\mathrm{b}}$ \\
44.9981 & $\mathrm{HCOO}^{-}$ & 44.9977 & $346.2^{\mathrm{b}}$ \\
45.9930 & $\mathrm{NO}_{2}^{-}$ & 45.9929 & $340^{\mathrm{b}}$ \\
59.0115 & $\mathrm{CH}_{3} \mathrm{COO}^{-}$ & 59.0133 & $348.6^{\mathrm{b}}$ \\
59.9825 & $\mathrm{CO}_{3}^{-}$ & 59.9847 & $\sim 324^{\mathrm{c}}$ \\
60.9905 & $\mathrm{HCO}_{3}^{-}$ & 60.9926 & $334.6^{\mathrm{b}}$ \\
76.9871 & $\mathrm{O}_{2}+\mathrm{HCOO}^{-}$ & 76.9875 & $/$ \\
93.0340 & $\mathrm{C}_{6} \mathrm{H}_{5} \mathrm{O}^{-}$ & 93.0340 & $349.2^{\mathrm{b}}$ \\
107.0495 & $\mathrm{CH}_{3} \mathrm{C}_{6} \mathrm{H}_{4} \mathrm{O}^{-}$ & 107.0497 & $\sim 350.3^{\mathrm{c}}$ \\
121.0295 & $\mathrm{C}_{6} \mathrm{H}_{5} \mathrm{COO}^{-}$ & 121.0290 & $340.1^{\mathrm{b}}$ \\
$57.0334^{\mathrm{d}}$ & $\mathrm{CH}_{3} \mathrm{COCH}_{2}^{-}$ & 57.0340 & $369.0^{\mathrm{b}}$ \\
$91.0530^{\mathrm{d}}$ & $\mathrm{C}_{6} \mathrm{H}_{5} \mathrm{CH}_{2}^{-}$ & 91.0548 & $382.4^{\mathrm{b}}$ \\
\hline
\end{tabular}

${ }^{a} \Delta H_{\text {acid }}$ gas-phase acidity for the corresponding acids of background ions.

bData obtained from reference [27].

'Data estimated using experimental data for structural analogs, with data from reference [27]. Uncertainties are estimated as being \pm 5 $\mathrm{kcal} / \mathrm{mol}$ for acidities, and $\pm 0.2 \mathrm{eV}$ for electron affinities.

${ }^{\mathrm{d} B o t h}$ anions only existed when $1 \%$ (vol/vol) di-tert-butyl peroxide was used as an additive in toluene.

through an EC mechanism. Both $\mathrm{O}_{2}$ and $\mathrm{NO}_{2}$ possess positive EAs as shown in Table 1.

Although the mass spectrometer used in this study discriminates against low $\mathrm{m} / \mathrm{z}$ ions, the existence of $\mathrm{O}_{2}^{-}$. was still directly observed in a spectrum as shown in Figure 2. This is very important because $\mathrm{O}_{2}^{-}$possesses the strongest gas-phase basicity of all background ions, as shown in Table 1, when toluene was exclusively used as both the solvent and dopant. The existence of other nonatmospheric gas ions in Figure 1 can possibly be interpreted through gas-phase reactions as previously reported by Traldi and coworkers [20]. However, we were unable to assign the $\mathrm{m} / \mathrm{z} 212.0735$ and 255.2310 ions probable chemical structures. The closest match to the $m / z 212.0735$ ion has an elemental composition of $\mathrm{C}_{13} \mathrm{H}_{10} \mathrm{NO}_{2}$ with $11 \mathrm{ppm}$ mass error. A product ion scan of the $\mathrm{m} / \mathrm{z} 212.0735$ ion generated more than eight fragment ions (data not shown). There is no elemental composition containing exclusively $\mathrm{C}, \mathrm{H}, \mathrm{O}$, and $\mathrm{N}$ for identification of the $\mathrm{m} / \mathrm{z} 255.2310$ ion with less than 250 ppm mass error. A product ion scan of the $\mathrm{m} / \mathrm{z} 255.2310$ ion generated only one small product ion by loss of a water molecule.

\section{EC and Dissociative EC}

Five nitro-aromatic compounds, including 1,3-DNB, 2-amino-4,6-DNT, 2,4-DNT, TNT, and 1,3,5-TNB, were analyzed using negative ion-APPI. The negative ionAPPI spectrum of a mixture of these five compounds produced from the consumption of $3.3 \mathrm{pg}(\mathrm{pg})$ of each analyte is illustrated in Figure 3. It can be seen that the ionization of 1,3-DNB and 1,3,5-TNB generated exclusively two types of ions, $\mathrm{M}^{-\cdot}$ and $[\mathrm{M}-\mathrm{NO}]^{-}$. It is noted that in Figure 3 the $\mathrm{M}^{-\cdot}$ ion of $1,3,5-\mathrm{TNB}$ is well separated from the isotopic peak of the background ion with $m / z 212.0741$.

The formation of $\mathrm{M}^{-\cdot}$ ions can be easily attributed to an EC mechanism since 1,3-DNB and 1,3,5-TNB possess positive EAs as shown in Table 1. However, the formation of $\left[\mathrm{M}-\mathrm{NO}^{-}\right.$ions can be interpreted as the result of either a dissociative EC mechanism or in-source fragmentation of the $\mathrm{M}^{-}$ions. If the latter was responsible, alteration of the in-source fragmentation parameters, such as source temperature and $\mathrm{DP}$ value, would result in an increase of the [M $\mathrm{NO}]^{-}$ion intensity and a simultaneous decrease of the $\mathrm{M}^{-\cdot}$ ion intensity. By altering the source temperature (using values of $150,250,350$, and $450^{\circ} \mathrm{C}$ ), the relative ion intensity between an $\mathrm{M}^{-}$ion and its corresponding $\left[\mathrm{M}-\mathrm{NO}^{-}\right.$ion did not change significantly. In contrast, altering the DP value (using values of $20,30,40,50$, and $70 \mathrm{~V}$ ) changed the relative ion intensity between an $[\mathrm{M}-\mathrm{NO}]^{-}$ion and its corresponding $\mathrm{M}^{-\cdot}$ ion from 1.0, 1.3, 2.1, 4.3 to 22.8 for 1,3-DNB, and $0.5,0.6,1.0,1.9$ to 17.2 for $1,3-\mathrm{DNB}$, respectively. We, therefore, concluded that formation of the $[\mathrm{M}-\mathrm{NO}]^{-}$ions were due to in-source fragmentation. This was further proven by collisionally induced dissociation (CID) of the $\mathrm{M}^{-\cdot}$ ions. Even when the collision energy (CE) was as low as $5 \mathrm{~V}$, the intensity of the $[\mathrm{M}-\mathrm{NO}]^{-}$ions for $1,3-\mathrm{DNB}$ and $1,3,5-\mathrm{TNB}$ reached $2 \%$ and $1 \%$ that of the $\mathrm{M}^{-\cdot}$ ions, respectively. The intensity of the $[\mathrm{M}-\mathrm{NO}]^{-}$ions for 1,3-DNB and 1,3,5-TNB reached a maximum when $\mathrm{CE}$ was increased to be 12 and $15 \mathrm{~V}$, respectively.

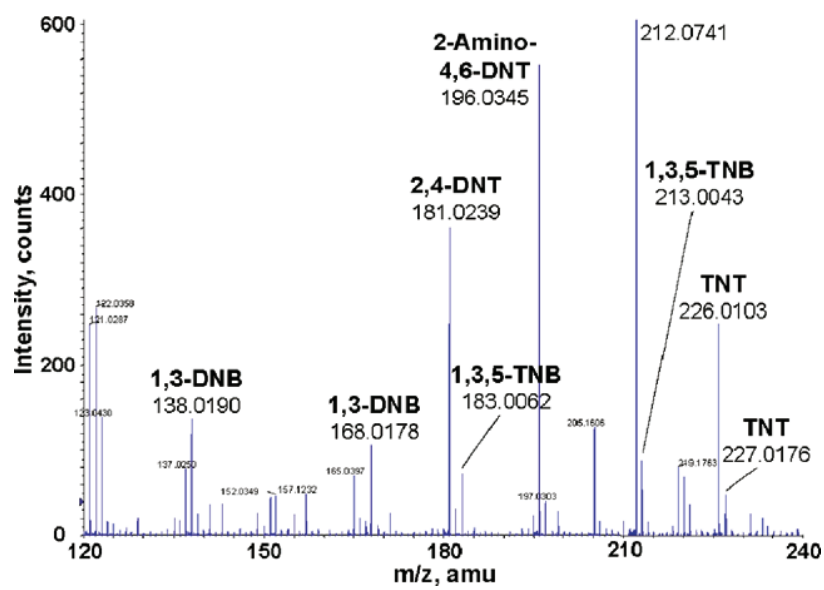

Figure 3. Negative ion-APPI spectrum of a mixture of 1,3-DNB, 2-amino-4,6-DNT, 2,4-DNT, TNT, and 1,3,5-TNB produced from the consumption of $3.3 \mathrm{pg}$ of each analyte (concentration 0.01 $\mathrm{ng} / \mu \mathrm{L}$ for each analyte, flow rate $20 \mu \mathrm{L} / \mathrm{min}$, acquisition time $1 \mathrm{~s}$ ). Mass spectrometric conditions are the same as described in the Experimental section, with the exception of source temperature maintained at $300{ }^{\circ} \mathrm{C}$. Ions of $\mathrm{m} / \mathrm{z} 138.0190$ and 168.0178 are interpreted as $\left[\mathrm{M}-\mathrm{NO}^{-}\right.$and $\mathrm{M}^{-}$ions, respectively, from 1,3-DNB. Ions of $\mathrm{m} / \mathrm{z} 183.0062$ and 213.0043 are interpreted as [M $-\mathrm{NO}^{-}$and $\mathrm{M}^{-\cdot}$ ions, respectively, from 1,3,5-TNB. Ions of $\mathrm{m} / \mathrm{z}$ 181.0239, 196.0345 and 226.0103 are interpreted as $[\mathrm{M}-\mathrm{H}]^{-}$ions from 2,4-DNT, 2-amino-4,6-DNT, and TNT, respectively. Ion of $\mathrm{m} / \mathrm{z} 227.0176$ is interpreted as $\mathbf{M}^{-\cdot}$ ion from TNT. 
Previously, Holmgren et al. [19] reported an ECAPCI spectrum of 1,3-DNB with the following ions and relative ion intensity: $168(46 \%), 138(100 \%)$, and 108 (4\%). Holmgren et al. [19] also reported an EC-APCI spectrum of 1,3,5-DNB with the following ions and relative ion intensity: $213(86 \%), 183(100 \%), 167(2 \%)$, and $125(4 \%)$.

\section{EC and Proton Transfer}

It can be seen from Figure 3 that the ionization of 2,4-DNT, TNT, and 2-amino-4,6-DNT generated mostly
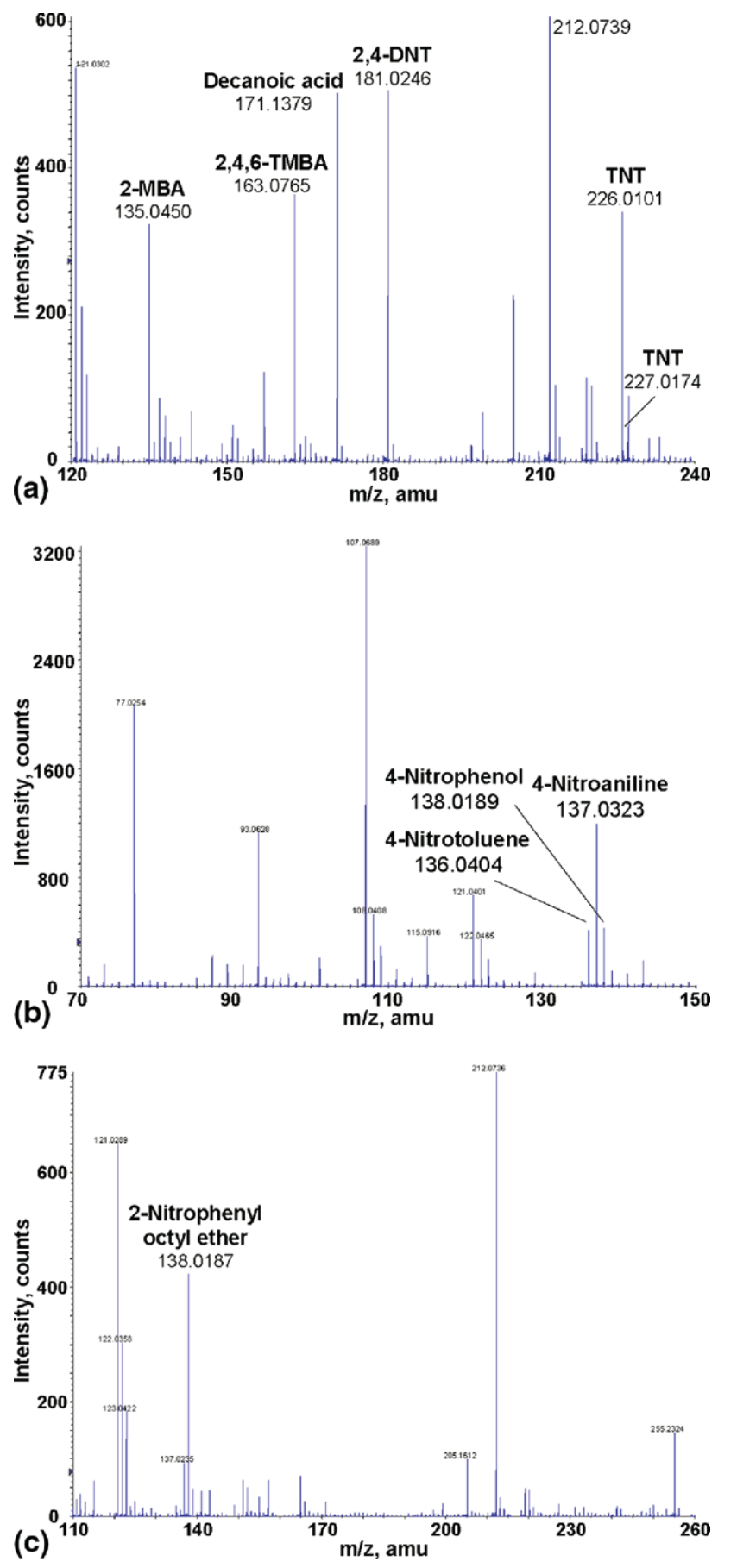

$[\mathrm{M}-\mathrm{H}]^{-}$ions. Of the three analytes, the molecular ion, i.e., $\mathrm{M}^{-}$, of only TNT was observed, with an intensity of $\sim 10 \%$ that of its respective $[\mathrm{M}-\mathrm{H}]^{-}$ion. Figure 3 also shows no obvious $[\mathrm{M}-\mathrm{NO}]^{-}$ion for 2-amino-4,6-DNT. It is noted, however, that the ion at $m / z 151$ in Figure 3 is a background ion rather than a $\left[\mathrm{M}-\mathrm{NO}^{-}\right.$ion from 2,4-DNT. Figure 4a shows no obvious $[\mathrm{M}-\mathrm{NO}]^{-}$ion for TNT, either.

Again, the formation of $\mathrm{M}^{-\cdot}$ ion from TNT can be easily attributed to an EC mechanism because TNT possesses a positive EA, as shown in Table 1. The formation of $[\mathrm{M}-\mathrm{H}]^{-}$ions should involve proton transfer between the analytes and the most basic background ion, i.e., $\mathrm{O}_{2}^{-*}$. It can be seen from Table 2 that $\mathrm{O}_{2}^{-}$. is a relatively strong gas-phase base because the gasphase acidity of $\mathrm{HO}_{2}$ is equal to $353.0 \mathrm{kcal} / \mathrm{mol}$. Proton transfer is possible for the analytes possessing gasphase acidity stronger than $353.0 \mathrm{kcal} / \mathrm{mol}$, which is true for 2,4-DNT, TNT, and 2-amino-4,6-DNT, as shown in Table 1. Although 1,3,5-TNB also possesses gas-phase acidity stronger than $353.0 \mathrm{kcal} / \mathrm{mol}$, steric hindrance may have prevented the loss of a proton.

Previous studies using EC-NICI or EC-APCI for the ionization of TNT typically generated complicated spectra. For example, Sigman et al. [12] reported an EC-NICI spectrum of TNT using methane as reagent gas with the following ions and relative ion intensity: $\mathrm{m} / \mathrm{z} 229(2 \%), 228(10 \%), \mathrm{m} / \mathrm{z} 227(100 \%), 210(16 \%), 198$ (3\%), $197(22 \%), 195(2 \%)$, and $167(3 \%)$. Fu et al. [18] reported an EC-APCI spectrum of TNT with the following ions and relative ion intensity: $m / z 245$ (12.7\%), 227 $(100 \%)$, and $197(59.1 \%)$. Holmgren et al. [19] reported an EC-APCI spectrum of TNT with the following ions and relative ion intensity: $\mathrm{m} / \mathrm{z} 227(50 \%), 226(50 \%), 210$ (100\%), 197 (69\%), $180(5 \%), 167$ (15\%), $152(13 \%), 137$ $(9 \%), 124(3 \%)$, and $109(3 \%)$. Negative ion-APPI offers an obvious advantage over EC-NICI and EC-APCI with fewer ionization products.

Figure 4. (a) Negative ion-APPI spectrum of a mixture of 2-MBA, 2,4,6-TMBA, decanoic acid, 2,4-DNT, and TNT produced from the consumption of $13.3 \mathrm{pg}$ each of 2-MBA, 2,4,6-TMBA, decanoic acid, plus $6.7 \mathrm{pg}$ each of 2,4-DNT and TNT (concentration 0.02 or $0.01 \mathrm{ng} / \mu \mathrm{L}$ for each analyte, flow rate $20 \mu \mathrm{L} / \mathrm{min}$, acquisition time $1 \mathrm{~s}) ;(\mathbf{b})$ negative ion-APPI spectrum of a mixture of 4-nitrotoluene, 4-nitroaniline, and 4-nitrophenol produced from the consumption of $330 \mathrm{pg}$ 4-nitrotoluene, $3.3 \mathrm{pg}$ 4-nitroaniline, and $0.67 \mathrm{pg}$ 4-nitrophenol (concentration 1, 0.01, and $0.002 \mathrm{ng} / \mu \mathrm{L}$ for each analyte, flow rate $20 \mu \mathrm{L} / \mathrm{min}$, acquisition time $1 \mathrm{~s}$ ); (c) negative ion-APPI spectrum of 2-nitrophenyl octyl ether produced from the consumption of $16.7 \mathrm{pg}$ analyte (concentration 0.05 $\mathrm{ng} / \mu \mathrm{L}$, flow rate $20 \mu \mathrm{L} / \mathrm{min}$, acquisition time $1 \mathrm{~s}$ ). Mass spectrometric conditions are the same as described in the Experimental section. Ions of $\mathrm{m} / \mathrm{z} 135.0450,163.0765,171.1376,181.0239$, and 226.0101 in (a) are interpreted as $[\mathrm{M}-\mathrm{H}]^{-}$ions from 2-MBA, 2,4,6-TMBA, decanoic acid, 2,4-DNT, and TNT, respectively. Ion of $\mathrm{m} / \mathrm{z} 227.0174$ in (a) is interpreted as $\mathbf{M}^{-\cdot}$ ion from TNT. Ions of $\mathrm{m} / \mathrm{z}$ 136.0404, 137.0323, and 138.0189 in (b) are interpreted as $[\mathrm{M}-\mathrm{H}]^{-}$ ions from 4-nitrotoluene, 4-nitroaniline, and 4-nitrophenol, respectively. Ion of $\mathrm{m} / \mathrm{z} 138.0187$ in (c) is interpreted as 2-nitrophenolate anion from 2-nitrophenyl octyl ether. 
The ionization efficiency of negative ion-APPI for TNT is also very high. The limit of detection (LOD), defined by detection of its $[\mathrm{M}-\mathrm{H}]^{-}$ion at a signal to noise ratio $(\mathrm{S} / \mathrm{N})$ of 3 , is about $90 \mathrm{fg}$ or $0.4 \mathrm{fmol}$. However, no direct comparison of negative ion-APPI with EC-NICI, EC-APCI or negative ion-ESI was performed in this study. In previously published studies, Sigman et al. [12] reported a LOD of 190 pg using GC/EC-NICI-MS and Holmgren et al. [19] reported a LOD of $4.0 \mathrm{ng}$ using LC/EC-APCI-MS.

\section{Dissociative EC and Proton Transfer}

In Figure 3, the formation of $[\mathrm{M}-\mathrm{H}]^{-}$ions from 2,4-DNT, TNT, and 2-amino-4,6-DNT may not only involve proton transfer as discussed above, but also possibly a dissociative EC mechanism. Dissociative EC with thermal electrons via a hydrogen atom loss to form the $[\mathrm{M}-\mathrm{H}]^{-}$ion should only be thermochemically accessible for acids stronger than $\Delta \mathrm{H}_{\text {acid }}=313.6 \mathrm{kcal} /$ $\mathrm{mol}$, the ionization energy of the hydrogen atom. Only TNT qualifies for this. However, excess energy in the free electrons in the source could possibly promote it for weaker acids. Three experiments were performed to investigate this possibility.

Figure 4a illustrates the analysis of 2-MBA, 2,4,6TMBA, decanoic acid, 2,4-DNT, and TNT using negative ion-APPI. In contrast, with 2,4-DNT and TNT, the carboxylic acids 2-MBA, 2,4,6-TMBA, and decanoic acid possess zero or negative EAs, and are still acidic enough to be deprotonated by $\mathrm{O}_{2}^{-}$, but not enough to qualify for dissociative EC. Therefore, only a proton transfer ionization mechanism should be responsible for the formation of their $[\mathrm{M}-\mathrm{H}]^{-}$ions. After normalization to the same amount of material, the higher ion intensity of $[\mathrm{M}-\mathrm{H}]^{-}$ions produced by 2,4-DNT and TNT may be a result of their positive EAs, and, therefore, a dissociative EC mechanism.

Figure $4 \mathrm{~b}$ depicts the analysis of 4-nitrotoluene, 4-nitroaniline, and 4-nitrophenol using negative ionAPPI. 4-Nitrotoluene is comparable to $\mathrm{O}_{2}^{-}$for proton transfer, so is expected to be the least sensitive to ionization of the three analytes. 4-Nitroaniline has a similar gas-phase acidity to 2-MBA, 2,4,6-TMBA, and decanoic acid, but its ion intensity is more than an order of magnitude higher after normalization to the same amount of material upon comparison of Figure 4a and $b$. In addition, it can be seen from Figure $4 b$ that when the functional groups of the nitroaromatics are changed from methyl-, to amino-, and finally to hydroxyl-, the intensity of $[\mathrm{M}-\mathrm{H}]^{-}$ions was greatly enhanced after normalization to the same amount of material. All three of these nitroaromatics, though, are far too weak as acids for dissociative $\mathrm{EC}$ with thermal electrons to be possible. There must be some reason that analytes with positive EAs yield much stronger $[\mathrm{M}-\mathrm{H}]^{-}$signals than analytes of comparable acidity but with zero or negative EAs. A possibility is a mechanism involving an alternate intermediate to that for simple proton transfer, but which yields the same product ions:

$$
\mathrm{O}_{2}^{-\cdot}+\mathrm{M} \rightarrow \mathrm{O}_{2}+\mathrm{M}^{-\cdot} \rightarrow \mathrm{HOO}+[\mathrm{M}-\mathrm{H}]^{-}
$$

This involves electron-transfer, followed by hydrogen atom transfer. Such a single electron transfer (SET) mechanism is known, but not common, in solution [21]. The first step would be exothermic for analytes with EAs more positive than that of $\mathrm{O}_{2}$ at $0.45 \mathrm{eV}$, thus providing a driving force, and possibly a rate constant favored over simple proton transfer. The existence of other ionization products from 4nitrotoluene, 4-nitroaniline, and 4-nitrophenol in Figure $5 \mathrm{~b}$ was also examined individually and appeared to be insignificant after background subtraction.

Figure $4 \mathrm{c}$ demonstrates the analysis of 2-nitrophenyl octyl ether using negative ion-APPI. A 2-nitrophenolate anion was exclusively observed. In this case a dissociative EC mechanism would yield a primary carboncentered radical, plus the ion indicated. Such a mechanism should be ca. $-10 \mathrm{kcal} / \mathrm{mol}$ favored in this case, based on thermochemistry in reference [26]. An alternate mechanism, involving $\mathrm{O}_{2}^{--}$acting as a base in an E2 elimination reaction to give 1-octene plus the phenoxide, cannot be ruled out. Previously, a dissociative EC mechanism was exclusively observed in the analysis of pentafluorobenzyl derivatized phenols [8]. Therefore, a dissociative EC mechanism may also be expected for other phenyl ethers with sufficiently positive EAs.

\section{Manipulating Proton Transfer}

Although a previous study by Kauppila et al. [11] implied the key role of $\mathrm{O}_{2}^{--}$in negative ion-APPI with regard to the

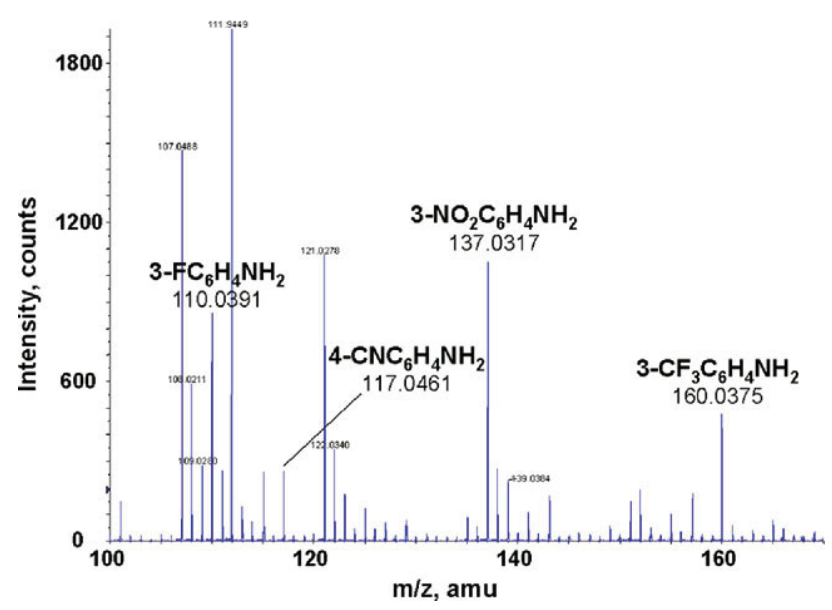

Figure 5. Negative ion-APPI spectrum of a mixture of 3-fluoroaniline, 3-trifluoromethylaniline, 3-nitroaniline, and 4-cyanoaniline produced from the consumption of $13.3 \mathrm{ng}$, 1.33 $\mathrm{ng}, 133 \mathrm{pg}$, and $13.3 \mathrm{pg}$ of each respective analyte (concentration $40,4,0.4$, and $0.04 \mathrm{ng} / \mu \mathrm{L}$ for each analyte, flow rate 20 $\mu \mathrm{L} / \mathrm{min}$, acquisition time $1 \mathrm{~s})$. Ions of $\mathrm{m} / \mathrm{z} 110.0391,117.0461$, 137.0317, and 160.0375 are interpreted as $[\mathrm{M}-\mathrm{H}]^{-}$ions from 3-fluoroaniline, 4-cyanoaniline, 3-nitroaniline and 3trifluoromethylaniline, respectively. 
proton transfer mechanism, no direct experimental evidence was provided. Here, we selected four aromatics (3-fluoroaniline, 3-trifluoromethylaniline, 3-nitroaniline, and 4-cyanoaniline) to fulfill this task. The gas-phase acidities of 3-fluoroaniline, 3-trifluoromethylaniline, 3nitroaniline, and 4-cyanoaniline are 361.2, 356.9, 352.3, and $348.8 \mathrm{kcal} / \mathrm{mol}$, respectively, as shown in Table 1 . Since the gas-phase acidity of $\mathrm{HO}_{2}$ is $353.0 \mathrm{kcal} / \mathrm{mol}$, [M - H] ions of 3-fluoroaniline and 3-trifluoromethylaniline should not theoretically be expected on reaction with $\mathrm{O}_{2}^{--}$; if only exothermic reactions are observed. Figure 5 displays a negative ion-APPI spectrum of a mixture of 3-fluoroaniline, 3-trifluoromethylaniline, 3-nitroaniline, and 4-cyanoaniline produced from the consumption of $13.3 \mathrm{ng}, 1.33 \mathrm{ng}, 133 \mathrm{pg}$, and $13.3 \mathrm{pg}$ of each respective analyte. After being normalized to the same amount of material, a significant decrease in ion intensity was revealed when the gas-phase acidity of the analytes changed from $348.8,352.3,356.9$ to $361.2 \mathrm{kcal} / \mathrm{mol}$, which is in good agreement with the above theoretical prediction.

The existence of $\mathrm{M}^{-\cdot}$ ions in Figure 5 was also examined after background subtraction since many low intensity background ions were observed in the studied mass range (data not shown). Apparently no significant $\mathrm{M}^{-\cdot}$ ions were detected.

Because even 1 ppm of oxygen as an impurity in the nebulizer and/or auxiliary gas is enough to affect negative ion-APPI, it is almost impossible to totally eliminate $\mathrm{O}_{2}^{-}$from the APPI source. However, manipulation of the proton transfer reactions in an APPI source can still be achieved by introduction of anions with stronger gas-phase basicity than $\mathrm{O}_{2}^{-}$. Di-tert-butyl peroxide may be able to provide such an anion, i.e., $\left(\mathrm{CH}_{3}\right)_{3} \mathrm{CO}^{-}$ (the gas-phase acidity of its corresponding acid is 374.6 $\mathrm{kcal} / \mathrm{mol}$ [27]), as the peroxide is able to undergo a dissociative EC reaction [22]. Therefore, the analysis of 3-fluoroaniline, 3-trifluoromethylaniline, 3-nitroaniline, and 4-cyanoaniline by negative ion-APPI was also performed with HPLC grade toluene as the solvent and 1\% (vol/vol) di-tert-butyl peroxide as an additive. The ion intensity of 3-fluoroaniline, 3-trifluoromethylaniline, 3nitroaniline, and 4-cyanoaniline increased $\sim 29,18,4$, and 3 times, respectively, after being normalized to the same amount of material.

The effect of di-tert-butyl peroxide concentration on negative ion-APPI efficiency was also examined and demonstrated in Figure 6. When the concentration was decreased from $1 \%$ to $0.5 \%$ and $0.1 \%$ (vol/vol), the analyte ion intensity was also decreased. However, when the concentration of di-tert-butyl peroxide was increased from $1 \%$ to $5 \%$ and $10 \%$ (vol/vol), significant enhancement of the ion intensity of the analytes was not observed.

The background spectrum of toluene with $1 \%$ (vol/ vol) di-tert-butyl peroxide by negative ion-APPI was examined and compared with Figure 1. Surprisingly, there was no obvious increase in the ion intensity of $\mathrm{m} / \mathrm{z}$ 73 ion, which existed in Figure 1 with low intensity.

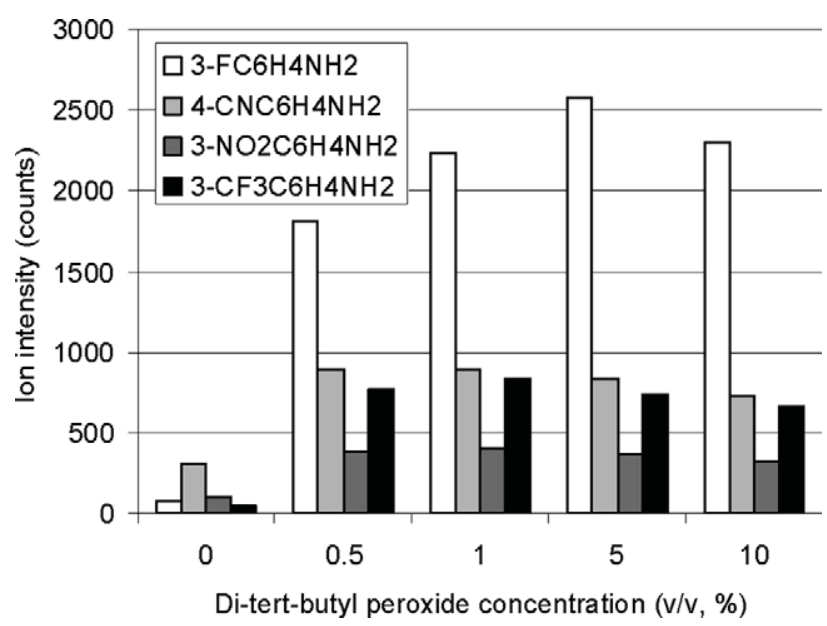

Figure 6. Effect of di-tert-butyl peroxide concentration on ionization efficiency of 3-fluoroaniline, 3-trifluoromethylaniline, 3nitroaniline, and 4-cyanoaniline (normalized respective consumption of each analyte: $1.33 \mathrm{ng}, 133 \mathrm{pg}, 13.3 \mathrm{pg}$, and $13.3 \mathrm{pg}$ ).

Therefore, there is no evidence corresponding to the existence of $\left(\mathrm{CH}_{3}\right)_{3} \mathrm{CO}^{-}$anion, as expected. However, an obvious additional $\mathrm{m} / \mathrm{z} 91.0530$ ion with an ion intensity of 374 counts was observed, whose closest elemental match is $\mathrm{C}_{7} \mathrm{H}_{7}$ with $19.5 \mathrm{ppm}$ mass error. This anion can be interpreted as deprotonated toluene, i.e., $\mathrm{C}_{6} \mathrm{H}_{5} \mathrm{CH}_{2}^{-}$. Toluene has a gas-phase acidity of $382.4 \mathrm{kcal} / \mathrm{mol}$. Therefore, the existence of $\mathrm{C}_{6} \mathrm{H}_{5} \mathrm{CH}_{2}^{-}$may be responsible for the enhanced deprotonation ability of negativeion APPI. Since the gas-phase acidity of toluene is 7.8 $\mathrm{kcal} / \mathrm{mol}$ weaker than that of $\left(\mathrm{CH}_{3}\right)_{3} \mathrm{COH}$, its dominant concentration in the APPI source may be responsible for its deprotonation. As shown in Figure 5, 3-fluoroaniline can still be deprotonated at a concentration of 40 $\mathrm{ng} / \mu \mathrm{L}$, even though its gas-phase acidity is $9.1 \mathrm{kcal} /$ mol weaker than that of $\mathrm{HO}_{2}$. In addition to the $\mathrm{m} / \mathrm{z}$ 91.0530 ion, another obvious additional background ion was $\mathrm{m} / \mathrm{z}$ 57.0334. Though its intensity was only 63 counts, it had increased from $\sim 1$ count in Figure 1. The closest elemental match for this anion is $\mathrm{C}_{3} \mathrm{H}_{5} \mathrm{O}$, with $11.2 \mathrm{ppm}$ mass error. This anion can be interpreted as deprotonated acetone, i.e., $\mathrm{CH}_{3} \mathrm{COCH}_{2}^{-}$. Acetone can be a decomposition product of di-tert-butyl peroxide under moderate temperature. Its gas-phase acidity is 369.0 $\mathrm{kcal} / \mathrm{mol}$, $5.6 \mathrm{kcal} / \mathrm{mol}$ stronger than that of $\left(\mathrm{CH}_{3}\right)_{3} \mathrm{COH}$. The existence of $\mathrm{CH}_{3} \mathrm{COCH}_{2}^{-}$in the APPI source is, therefore, understandable.

\section{Anion Attachment}

Anion attachment was primarily observed and studied in NICI using halide ions as the reactant. Dougherty et al. [23] showed that a variety of organic compounds, including aromatic and aliphatic carboxylic acids, amides, amino acids, aromatic amines, and phenols, displayed strong chloride attachment. Caldwell et al. [24] demonstrated that the highest sensitivity of halide 
attachment was for strong acids with $\Delta \mathrm{H}_{\text {acid }}$ values stronger than $350 \mathrm{kcal} / \mathrm{mol}$.

With negative ion-APPI, our previous study [8] indicated that halogenated solvents were inappropriate for use. Due to their positive EAs, they can capture thermal electrons and, consequently, prevent ionization of analytes through EC, dissociative EC, and/or proton transfer mechanisms. In the present study, the background toluene spectra were acquired after 1\% (vol/ vol) methylene chloride, bromoethane, or iodoethane were added (data not shown). Highly abundant halide ions were observed, as were clusters of halide ions for bromoethane and iodoethane. Meanwhile, the abundance of the anions observed in Figure 2 was significantly decreased. However, halide attachment to the acids responsible for the anions observed in Figure 2 were not found in the background spectra, indicating inefficient halide attachment to strong acids with $\Delta \mathrm{H}_{\text {acid }}$ values stronger than $350 \mathrm{kcal} / \mathrm{mol}$ for negative ionAPPI. This differs from NICI as reported by Caldwell et al. [24]. This was further proven by the analysis of 2-MBA, 2,4,6-TMBA, and decanoic acid using toluene with $1 \%$ (vol/vol) methylene chloride as solvent (data not shown). For all three of the carboxylic acids, [M $\mathrm{H}]^{-}$ions were primarily observed without significant $[\mathrm{M}+\mathrm{Cl}]^{-}$ions. In addition, the intensity of the $[\mathrm{M}-$ $\mathrm{H}]^{-}$ions was decreased more than a decade in comparison to that in Figure 4a after intensity normalization for the same amount of material.

The competition between deprotonation and halide attachment was observed in the analysis of PEG methyl ether 750. When pure toluene was used as the solvent, the negative ion-APPI spectrum of PEG methyl ether 750 showed $\left[\mathrm{CH}_{3} \mathrm{O}\left(\mathrm{CH}_{2} \mathrm{CH}_{2} \mathrm{O}\right)_{n}\right]^{-}$ions (data not shown). When toluene with $1 \%$ methylene chloride was used as the solvent, the $\left[\mathrm{CH}_{3} \mathrm{O}\left(\mathrm{CH}_{2} \mathrm{CH}_{2} \mathrm{O}\right)_{n}\right]^{-}$ions were still observed, but with slightly enhanced intensity, as shown in Figure $7 \mathrm{a}$. In addition, a series of $\left[\mathrm{CH}_{3} \mathrm{O}\right.$ $\left.\left(\mathrm{CH}_{2} \mathrm{CH}_{2} \mathrm{O}\right)_{n} \mathrm{HCl}\right]^{-}$ions were also observed for $n \geq 6$, most likely representing the molecular adducts of PEG methyl ether 750. For $n=11$, the ion intensity ratio between the $\left[\mathrm{CH}_{3} \mathrm{O}\left(\mathrm{CH}_{2} \mathrm{CH}_{2} \mathrm{O}\right)_{\mathrm{n}} \mathrm{HCl}\right]^{-}$and $\left[\mathrm{CH}_{3} \mathrm{O}\left(\mathrm{CH}_{2} \mathrm{CH}_{2} \mathrm{O}\right)_{n}\right]^{-}$ions was about 1:1. For $n>11$, the attachment/deprotonation ratio was even larger.

The analytical potential of an anion attachment ionization mechanism in negative ion-APPI is demonstrated in Figure $7 \mathrm{~b}$ for the analysis of a mixture of RDX and HMX. As shown in Table 1, RDX and HMX do not have positive EAs or sufficient gas-phase acidity to be ionized by EC, dissociative $\mathrm{EC}$, or proton transfer. However, their chloride attachment was so efficient that the limit of detection (LOD), defined by detection of their $[\mathrm{M}+\mathrm{Cl}]^{-}$ions at a signal to noise ratio $(\mathrm{S} / \mathrm{N})$ of 3, was estimated to be 424 and $64 \mathrm{fg}$ or 1.9 and $0.2 \mathrm{fmol}$, respectively. Previously, Holmgren et al. [19] reported the analysis of RDX and HMX by LC/negative ionAPCI-MS through chloride attachment with LOD of 3.3 and $1.7 \mathrm{ng}$, respectively. HMX was also analyzed via anion attachment by Pan et al. [25] using LC/negative
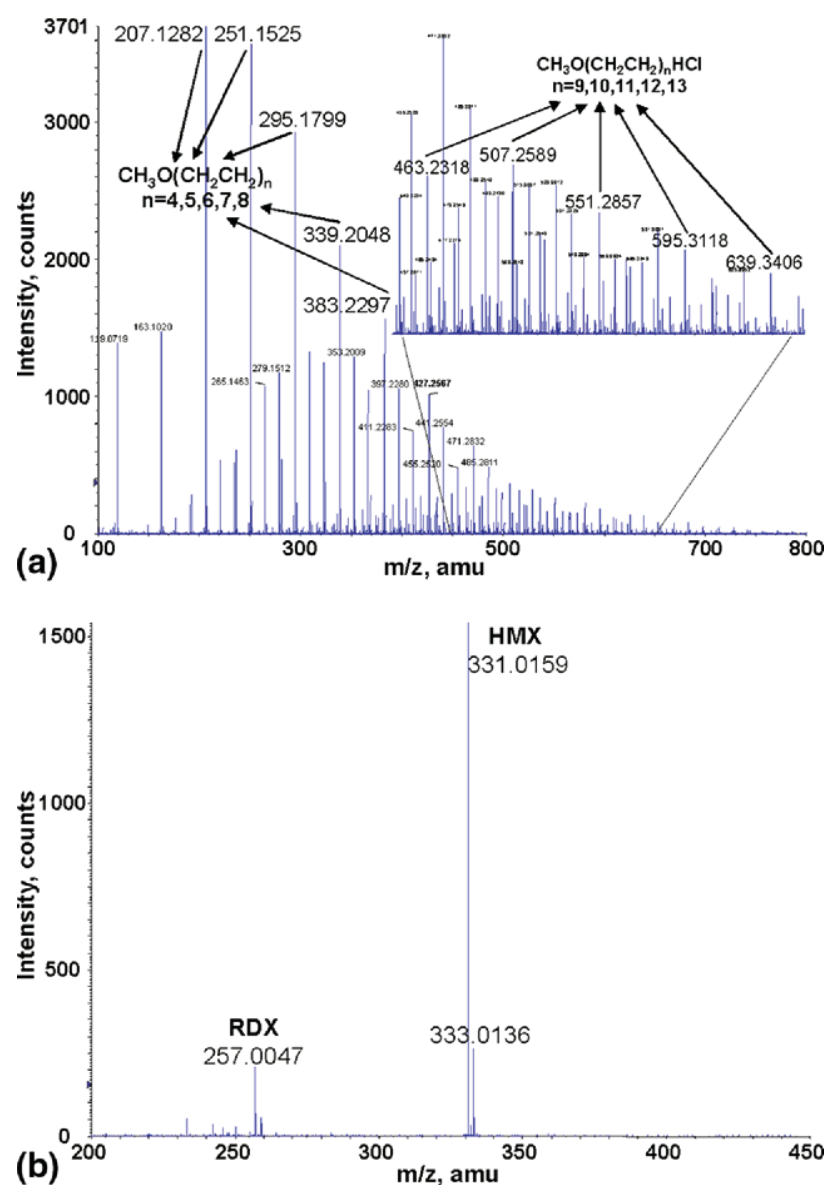

Figure 7. (a) Negative ion-APPI spectrum of poly(ethylene glycol) methyl ether with average M.W. 750 from the consumption of $33 \mathrm{pL}$ of the analyte (concentration $0.1 \mathrm{~nL} / \mu \mathrm{L}$, flow rate 20 $\mu \mathrm{L} / \mathrm{min}$, acquisition time $1 \mathrm{~s}$ ); (b) negative ion-APPI spectrum of a mixture of RDX and HMX produced from the consumption of 33 pg of each analyte (concentration $0.1 \mathrm{ng} / \mu \mathrm{L}$ for each analyte, flow rate $20 \mu \mathrm{L} / \mathrm{min}$, acquisition time $1 \mathrm{~s}$ ). Mass spectrometric conditions are GS1, 30; GS2, 30; CUR, 40; IS, -1900 V; TEM, 350 ${ }^{\circ}$; DP, $-25 \mathrm{~V} ; \mathrm{FP},-80 \mathrm{~V} ; \mathrm{DP} 2,-12 \mathrm{~V}$; and CAD (collision gas), 3. Ions of $\mathrm{m} / \mathrm{z} 257.0047$ and 331.0159 in $(\mathbf{b})$ are interpreted as $[\mathrm{M}+\mathrm{Cl}]^{-}$ions from RDX and HMX, respectively.

ion-ESI-MS. Results indicated that acetate attachment was more efficient than formate, propionate, nitrate, chloride, nitrite, and nitrate with a LOD of $0.78 \mathrm{pg}$.

Four concentrations of methylene chloride [0.1, 0.5, 1.0 , and $2.0 \%(\mathrm{vol} / \mathrm{vol})]$ in toluene were tested to determine the optimum conditions for chloride attachment in the analysis of RDX and HMX. Highly abundant $[\mathrm{M}+\mathrm{Cl}]^{-}$ions were observed even with $0.1 \%$ ( vol/vol) methylene chloride. The intensity of the $[\mathrm{M}+$ $\mathrm{Cl}^{-}$ions increased with the concentration of methylene chloride up to $1 \%$ (vol/vol).

In comparison to $1 \%(\mathrm{vol} / \mathrm{vol})$ methylene chloride, the intensity of the $[\mathrm{M}+\mathrm{Br}]^{-}$ions of RDX and HMX became lower with $1 \%$ (vol/vol) bromoethane, and that of the $[\mathrm{M}+\mathrm{I}]^{-}$ions became even lower with $1 \%$ (vol/vol) iodoethane. 


\section{Conclusions}

Three ionization mechanisms were shown to be involved in negative ion-APPI of nitroaromatics; EC, dissociative $\mathrm{EC}$, and proton transfer. These ionization mechanisms may compete with each other and result in multiple ionization products from the same molecule. Moreover, dissociative EC and proton transfer can combine to generate the same $[\mathrm{M}-\mathrm{H}]^{-}$ions. There is also a possibility, in need of further investigation, that an alternate electron/hydrogen transfer mechanism, rather than a simple proton transfer, is involved in the formation of $[\mathrm{M}-\mathrm{H}]^{-}$ions from analytes with both gas-phase acidity and positive EAs. For ease of deprotonation with nitroaromatics, the order was found to be methyl- $<$ amino- $<$ hydroxyl- functional groups attaching to the benzene ring. A dissociative EC mechanism is likely for 2-nitrophenyl octyl ether and expected for other phenyl ethers with sufficient positive EAs.

It is well known that the EC ability of an electrophoric compound is determined by its EA value. It is currently impossible to predict the dissociative EC ability of an electrophoric compound. However, this study certainly provides guidelines. It can be especially useful to guide the design of electrophoric derivatization reagents. Nitroaromatics have been used as electrophoric derivatization reagents in LC/EC-APCI-MS for the analysis of amines, aldehydes, ketones, 25hydroxylvitamin D-3, and neurosteroids [14-17].

This study provided experimental evidence that $\mathrm{O}_{2}^{-}$. plays a key role in dopant assisted negative ion-APPI for the formation of $[\mathrm{M}-\mathrm{H}]^{-}$ions through proton transfer. The existence of $\mathrm{O}_{2}^{-\cdot}$ in an APPI source was directly observed in a spectrum of background ions when toluene was used exclusively as solvent and/or dopant. While analytes with gas-phase acidity, i.e., $\Delta \mathrm{H}_{\text {acid, }}$ a few $\mathrm{kcal} / \mathrm{mol}$ lower than $\mathrm{HO}_{2}$ could be efficiently deprotonated, analytes with gas-phase acidity a few $\mathrm{kcal} / \mathrm{mol}$ higher than $\mathrm{HO}_{2}$ could not be efficiently deprotonated. Introduction of anions more basic than $\mathrm{O}_{2}^{-}$, i.e., $\mathrm{C}_{6} \mathrm{H}_{5} \mathrm{CH}_{2}^{-}$, into the APPI source through the addition of di-tert-butyl peroxide in the solvent and/or dopant enhanced the deprotonation ability of negative ion-APPI. Better deprotonation ability for negative ion-APPI cannot be expected if the solvents and/or buffer reagents have gas-phase acidity higher than toluene.

Anion attachment is a novel ionization mechanism discovered for negative ion-APPI in this study. It offers great analytical potential because it may lead to efficient ionization of compounds, which cannot be ionized by EC, dissociative EC, or proton transfer ionization mechanisms. These compounds usually lack polarity and may be thermo-labile and, therefore, difficult to be ionized by any other available ionization methods. Anion attachment to these compounds may be a result of hydrogen bonding, dipole attraction, and/or polarization, which will be studied in detail in the future.
Nevertheless, with the available four ionization mechanisms, it becomes obvious that negative ion-APPI is able to ionize a wider range of compounds than NICI, negative ion-APCI or negative ion-ESI. This is especially true for low polarity compounds.

Although the effect of solvents and buffer reagents on negative ion-APPI is not the focus of this study, it can be predicted according to the ionization mechanisms. Halogenated solvents and/or buffer reagents possessing positive EAs will block EC, dissociative EC, and proton transfer because they will consume thermal electrons. Solvents and/or buffers possessing gas-phase acidity stronger than thermal electrons, i.e., $\Delta \mathrm{H}_{\text {acid }}<$ $313.6 \mathrm{kcal} / \mathrm{mol}$, will hinder EC, dissociative EC, and proton transfer for the same reason. The efficiency of proton transfer will be decreased when solvents or buffer reagents possess gas-phase acidities stronger than $\mathrm{HO}_{2}$. Therefore, the commonly used buffer reagents in negative ion-ESI and APCI, such as formic acid, acetic acid, trifluoroacetic acid, and their ammonium salts, are inappropriate for negative ion-APPI. This has also been proven by previous studies $[8,11]$.

\section{Acknowledgments}

LS thanks Dr. David C. Baker for providing some of the compounds used in this study. The authors greatly appreciate financial support from the National Science Foundation for the Mass Spectrometry Center of the University of Tennessee (CHE-0130752).

\section{References}

1. Robb, D. B.; Covey, T. R.; Bruins, A. P. Atmospheric Pressure Photoionization: An Ionization Method for Liquid Chromatography-Mass Spectrometry. Anal. Chem. 2000, 72(15), 3653-3659.

2. Hanold, K. A.; Fischer, S. M.; Cormia, P. H.; Miller, C. E.; Syage, J. A. Atmospheric Pressure Photoionization. 1. General Properties for LC/ MS. Anal. Chem. 2004, 76(10), 2842-2851.

3. Hayen, H.; Karst, U. Strategies for the Liquid Chromatographic-Mass Spectrometric Analysis of Nonpolar Compounds. J. Chromatogr. A 2003, 1000(1/2):549-565.

4. Raffaelli, A.; Saba, A. Atmospheric Pressure Photoionization Mass Spectrometry. Mass Spectrom. Rev. 2003, 22(5), 318-331.

5. Bos, S. J.; van Leeuwen, S. M.; Karst, U. From Fundamentals to Applications: Recent Developments in Atmospheric Pressure Photoionization Mass Spectrometry. Anal. Bioanal. Chem. 2006, 384(1), 85-99.

6. Leis, H. J.; Fauler, G.; Rechberger, G. N.; Windischhofer, W. ElectronCapture Mass Spectrometry: A Powerful Tool in Biomedical Trace Level Analysis. Curr. Med. Chem. 2004, 11(12), 1585-1594.

7. Singh, G.; Gutierrez, A.; Xu, K. Y.; Blair, I. A. Liquid Chromatography/ Electron Capture Atmospheric Pressure Chemical Ionization/Mass Spectrometry: Analysis of Pentafluorobenzyl Derivatives of Biomolecules and Drugs in the Attomole Range. Anal. Chem. 2000, 72(14), 3007-3013.

8. Song, L.; Wellman, A. D.; Yao, H.; Adcock, J. Electron Capture Atmospheric Pressure Photoionization Mass Spectrometry: Analysis of Fullerenes, Perfluorinated Compounds, and Pentafluorobenzyl Derivatives. Rapid Commun. Mass Spectrom. 2007, 21(8), 1343-1351.

9. Kauppila, T. J.; Kuuranne, T.; Meurer, E. C.; Eberlin, M. N.; Kotiaho, T.; Kostiainen, R. Atmospheric Pressure Photoionization Mass Spectrometry. Ionization Mechanism and the Effect of Solvent on the Ionization of Naphthalenes. Anal. Chem. 2002, 74(21), 5470-5479.

10. Basso, E.; Marotta, E.; Seraglia, R.; Tubaro, M.; Traldi, P. On the Formation of Negative Ions in Atmospheric Pressure Photoionization Conditions. J. Mass Spectrom. 2003, 38(10), 1113-1115.

11. Kauppila, T. J.; Kotiaho, T.; Kostiainen, R.; Bruins, A. P. Negative Ion-Atmospheric Pressure Photoionization-Mass Spectrometry. J. Am. Soc. Mass Spectrom. 2004, 15(2), 203-211.

12. Sigman, M. E.; Ma, C. Y. In-injection Port Thermal Desorption for Explosives Trace Evidence Analysis. Anal. Chem. 1999, 71(19), 4119 4124. 
13. Sigman, M. E.; Ma, C. Y. Detection Limits for GC/MS Analysis of Organic Explosives. J. Forensic Sci. 2001, 46(1), 6-11.

14. Hayen, H.; Jachmann, N.; Vogel, M.; Karst, U. LC-Electron Capture APCI-MS for the Determination of Nitroaromatic Compounds. Analyst 2002, 127(8), 1027-1030.

15. Hayen, H.; Jachmann, N.; Vogel, M.; Karst, U. LC-Electron CaptureAPCI(-) MS Determination of Nitrobenzoxadiazole Derivatives. Analyst 2003, 128(11), 1365-1372.

16. Higashi, T.; Yamauchi, A.; Shimada, K. Application of 4-(4-Nitrophenyl)1,2,4-Triazoline-3,5-(Dione to Analysis of 25-Hydroxyvitamin D-3 in Human Plasma by Liquid Chromatography/Electron Capture Atmospheric Pressure Chemical Ionization-Mass Spectrometry. Anal. Sci. 2003, 19(6), 941-943.

17. Higashi, T.; Takido, N.; Shimada, K. Studies on Neurosteroids XVII. Analysis of Stress-Induced Changes in Neurosteroid Levels in Rat Brains Using Liquid Chromatography-Electron Capture Atmospheric Pressure Chemical Ionization-Mass Spectrometry. Steroids 2005, 70(1), $1-11$.

18. Fu, X. F.; Zhang, Y.; Shi, S. H.; Gao, F.; Wen, D. W.; Li, W.; Liao, Y. P.; Liu, H. W. Fragmentation Study of Hexanitrostilbene by Ion Trap Multiple Mass Spectrometry and Analysis by Liquid Chromatography/ Mass Spectrometry. Rapid Commun. Mass Spectrom. 2006, 20(19), 29062914.

19. Holmgren, E.; Carlsson, H.; Goede, P.; Crescenzi, C. Determination and Characterization of Organic Explosives Using Porous Graphitic Carbon and Liquid Chromatography-Atmospheric Pressure Chemical Ionization Mass Spectrometry. J. Chromatogr. A 2005, 1099(1/2):127-135
20. Tubaro, M.; Marotta, E.; Seraglia, R.; Traldi, P. Atmospheric Pressure Photoionization Mechanisms. 2. The Case of Benzene and Toluene. Rapid Commun. Mass Spectrom. 2003, 17(21), 2423-2429.

21. Eberson, L. Electron-Transfer Reactions in Organic-Chemistry. Adv. Phys. Org. Chem. 1982, 18, 79-185.

22. Reed, K. J.; Brauman, J. I. Electron Affinities of Alkoxy Radicals and Bond-Dissociation Energies in Aliphatic-Alcohols. I. Am. Chem. Soc. 1975, 97(6), 1625-1626.

23. Tannenbaum, H. P.; Roberts, J. D.; Dougherty, R. C. Negative Chemical Ionization Mass-Spectrometry-Chloride Attachment Spectra. Anal. Chem. 1975, 47(1), 49-54.

24. Caldwell, G. W.; Masucci, J. A.; Ikonomou, M. G. Negative-Ion Chemical Ionization Mass-Spectrometry Binding of Molecules to Bromide and Iodide Anions. Org. Mass Spectrom. 1989, 24(1), 8-14.

25. Pan, X. P.; Tian, K.; Jones, L. E.; Cobb, G. P. Method Optimization for Quantitative Analysis of Octahydro-1,3,5,7-Tetranitro-1,3,5,7-Tetrazocine (HMX) by Liquid Chromatography-Electrospray Ionization Mass Spectrometry. Talanta 2006, 70(2), 455-459.

26. Pratt, D. A.; deHeer, M. I.; Mulder, P.; Ingold, K. U. J. Am. Chem. Soc 2003, 123, 5518; Fujio, M.; McIver, R. T., Jr.; Taft, R. W. Effects on the Acidities of Phenols from Specific Substituent-Solvent Interactions Inherent Substituent Parameters from Gas Phase-Acidities. J. Am. Chem. Soc. 1981, 103, 4017.

27. Bartmess, J. E. Negative Ion Energetics Data. In NIST Chemistry WebBook (http:/ / webbook.nist.gov); Linstrom, P. J.; Mallard, W. G. Eds; NIST Standard Reference Database Number 69, National Institute of Standards and Technology: Gaithersburg, MD, 2005. 